\title{
Sex-specific differences in injury types among basketball players
}

\author{
This article was published in the following Dove Press journal: \\ Open Access Journal of Sports Medicine \\ 29 December 2014 \\ Number of times this article has been viewed
}

\section{Eri Ito \\ Jun Iwamoto \\ Koichiro Azuma \\ Hideo Matsumoto \\ Institute for Integrated Sports Medicine, Keio University School of Medicine, Tokyo, Japan}

Correspondence: Eri Ito Institute for Integrated Sports Medicine, Keio University School of Medicine, 35 Shinanomachi, Shinjuku-ku,

Tokyo 160-8582, Japan

Tel +8 I 33353 | 2 | |

Fax +8I 352699054

Email b055a004n@yahoo.co.jp
Abstract: The purpose of the present study was to investigate sex-specific differences in injury types among basketball players. According to our database, during the 20 -year period between October 1991 and June 2011, 1,219 basketball players (640 males and 579 females) consulted our sports medicine clinic; in total, 1,414 injuries in basketball players ( 729 injuries in males and 685 injuries in females) were recorded. The mean age of patients was 19.6 years. The most common injury site was the knee, followed by the foot and ankle, lower back, and upper extremities. There was a higher proportion of female players presenting with a knee injury, compared with male players ( $50.4 \%$ vs $41.7 \%$ ), and a lower proportion of female players presenting with an upper extremity injury ( $5.1 \%$ vs $9.7 \%$ ). The proportion of anterior cruciate ligament injury in the $10-19$-year-old age group was higher among female players than among male players $(45.9 \% \mathrm{vs}$ $22.1 \%$ ), while the proportions of Osgood-Schlatter disease in the 10-19-year-old age group and jumper's knee (patellar and femoral tendinopathy) in the 20-29-year-old age group were higher among male players than among female players (12.5\% vs $1.8 \%$ and $14.6 \%$ vs $3.7 \%$, respectively). However, the proportions of other injuries did not differ significantly between male and female players. The present observational study, which was performed using a retrospective case-series design, showed the existence of sex-specific differences in knee injuries sustained while participating in basketball.

Keywords: sports injury, sex, anterior cruciate ligament injury, Osgood-Schlatter disease, basketball

\section{Introduction}

Sports epidemiology has been increasingly recognized as a powerful tool for evaluating injury types, trends, and mechanisms, and for identifying potentially modifiable risk factors for sports injuries. Basketball is a popular sport, and professional basketball has been established in Japan (bj league) as well as the USA (National Basketball Association and Women's National Basketball Association). The lower extremities are the most commonly injured body area in basketball players, and a lateral ankle sprain is the most common diagnosis. ${ }^{1-3}$ In particular, the incidence of game-related knee injuries is reportedly higher in female players than in male players. ${ }^{1}$

Basketball is also popular among teenagers. The surveillance of sports injuries in junior Japanese athletes has clarified that the incidence (cases/100,000 athlete-years) of sports injuries among junior high school and high school athletes was relatively high $(13,411)$ among basketball players, with rugby and judo athletes having higher incidences $\left(29,204\right.$ and 16,592, respectively). ${ }^{4}$ In particular, the incidence of (cases/100,000 athlete-years) anterior cruciate ligament (ACL) injury was higher 
among female athletes than among male athletes (154 and 48 , respectively), ${ }^{4}$ suggesting the presence of a sex-specific difference in ACL injury in young athletes, including basketball players.

Because sports injuries related to trauma are the most common subjects of analysis, sex-specific differences in sports injuries related to over-use have been less well clarified. The purpose of the present study was to investigate sex-specific differences in traumatic and over-use injuries sustained by basketball players.

\section{Subjects and methods}

In our Sports Medicine Clinic, the age, sex, sports activities, sports injuries, and other personal data of athletes are thoroughly assessed by medical doctors (orthopedic surgeons). These data have been recorded and maintained in our computer system. According to our database, during the 20-year period between October 1991 and June 2011, 1,219 basketball players (age range: 8-39 years, 640 males and 579 females) consulted our sports medicine clinic; in total, 1,414 injuries in basketball players (729 injuries in males and 685 injuries in females) were recorded.

The proportions of common injuries caused by sport activities were investigated in basketball players, and sexspecific differences in the types of common injuries associated with playing basketball were clarified.

An unpaired Student's $t$-test was used to compare the ages of male and female basketball players. A Fisher's exact test was used to determine the significance of sex-specific differences in the types of injuries. The statistical analyses were performed using SPSS version 11.5J (SPSS Inc., Chicago, IL, USA). A significance level of $P<0.05$ was used for all the comparisons.

\section{Results}

\section{Age of study subjects}

The mean age of all the patients was 19.6 years (range: 8-39 years). The mean age was slightly, but significantly, younger among females than among males (mean: 20.1 years for males, and 19.0 years for females).

Table 1 shows the age distribution of the sports injuries. The proportion of sports injuries in the 10-19-year-old age group was the greatest, followed by the 20-29-year-old and the 30-39-year-old age groups. The proportion of cases in the 10-19-year-old age group was significantly higher among females than among males (61.5\% vs $49.9 \%)$, while that in the 30-39-year-old age group was significantly higher among males than among females (7.1\% vs $2.5 \%)$.
Table I Age distribution of sports injuries

\begin{tabular}{lllll}
\hline Sex & $\begin{array}{l}<10 \text { years, } \\
\mathbf{n}(\%)\end{array}$ & $\begin{array}{l}\text { 10-19 years, } \\
\mathbf{n}(\%)\end{array}$ & $\begin{array}{l}\text { 20-29 years, } \\
\mathbf{n}(\%)\end{array}$ & $\begin{array}{l}\text { 30-39 years, } \\
\mathbf{n}(\%)\end{array}$ \\
\hline Male & $0(0)$ & $364(49.9)$ & $313(42.9)$ & $52(7.1)$ \\
Female & $2(0.3)$ & $421(61.5)^{*}$ & $245(35.8)$ & $17(2.5)^{*}$ \\
\hline
\end{tabular}

Notes: The proportion of sports injuries in the 10-19-year-old age group was the greatest, followed by the 20-29-year-old and 30-39-year-old age groups. The proportion of cases in the 10-19-year-old age group was significantly higher in females than in males, while that in the 30-39-year-old group was significantly higher in males than in females. $* P<0.05$ male vs female (Fisher's exact test).

\section{Proportions of injury sites}

Table 2 shows the common injury sites in basketball players. The most common injury site was the knee (male: $41.7 \%$, female: $50.4 \%$ ), followed by the foot and ankle (male: $24.8 \%$, female: $23.8 \%$ ), lower back (male: $11.8 \%$, female: $11.4 \%$ ), and upper extremity (male: $9.7 \%$, female: $5.1 \%$ ). There was a higher proportion of females than males presenting with a knee injury, and there was a higher proportion of males than females presenting with upper extremity injuries.

In particular, among all the age groups, a higher proportion of knee injury among female players and a higher proportion of upper extremity injury among male players were recognized in the 10-19-year-old age group.

\section{Proportions of main injuries}

\section{Knee injuries}

Figure 1 shows that the proportion of ACL injury was the highest (male: $30.3 \%$, female: $48.7 \%$ ), followed by meniscus injury (male: $13.2 \%$, female: $9.6 \%$ ), jumper's knee (patellar and femoral tendinitis) (male: 14.8\%, female: $7.2 \%$ ), and Osgood-Schlatter disease (male: $5.6 \%$, female: $1.2 \%$ ). There was a higher proportion of females than males presenting

Table 2 Common injury sites according to age group

\begin{tabular}{|c|c|c|c|c|}
\hline Injury site & All (\%) & $\begin{array}{l}10-19 \text { years } \\
(\%)\end{array}$ & $\begin{array}{l}20-29 \text { years } \\
\text { (\%) }\end{array}$ & $\begin{array}{l}30-39 \text { years } \\
\text { (\%) }\end{array}$ \\
\hline \multicolumn{5}{|l|}{ Knee } \\
\hline Male & 41.7 & 37.4 & 43.8 & 59.6 \\
\hline Female & $50.4^{*}$ & $52.7^{*}$ & 44.5 & 70.6 \\
\hline \multicolumn{5}{|c|}{ Foot and ankle } \\
\hline Male & 24.8 & 26.4 & 24.3 & 17.3 \\
\hline Female & 23.8 & 21.9 & 28.2 & 11.8 \\
\hline \multicolumn{5}{|l|}{ Lower back } \\
\hline Male & 11.8 & 14.0 & 9.9 & 7.7 \\
\hline Female & 11.4 & 11.4 & 11.8 & 5.9 \\
\hline \multicolumn{5}{|c|}{ Upper extremity } \\
\hline Male & 9.7 & 8.2 & 11.8 & 7.7 \\
\hline Female & $5.1^{*}$ & $4.5^{*}$ & 6.5 & 0.0 \\
\hline
\end{tabular}

Notes: The most common injury site was the knee, followed by the foot and ankle, lower back, and upper extremity. There was a higher proportion of females than males presenting with a knee injury, and there was a higher proportion of males than females presenting with upper extremity injuries. Higher proportions of knee injury among female players and upper extremity injury among male players were recognized in the 10-19-year-old age group. ${ }^{*}<0.05$ male vs female (Fisher's exact test). 


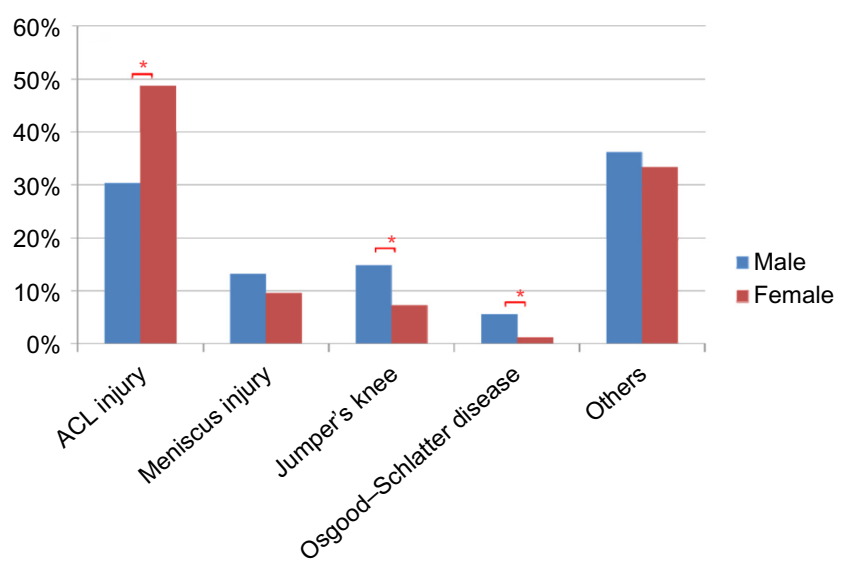

Figure I Knee injuries.

Notes: The graph shows the proportion of main injuries of the knee in male and female basketball players. The proportion of $A C L$ injury was the highest, followed by meniscus injury, jumper's knee (patellar and femoral tendinitis), and OsgoodSchlatter disease. There was a higher proportion of females than males presenting with $A C L$ injury, and there was a higher proportion of males than females presenting with jumper's knee (patellar and femoral tendinopathy) and Osgood-Schlatter disease. $* P<0.05$ male vs female (Fisher's exact test).

Abbreviation: $\mathrm{ACL}$, anterior cruciate ligament.

with ACL injury, and there was a higher proportion of males than females presenting with jumper's knee (patellar and femoral tendinopathy) and Osgood-Schlatter disease.

In particular, among all the age groups, a higher proportion of ACL injury in female players than in male players was recognized in the $10-19$-year-old age group ( $45.9 \%$ vs $22.1 \%$ ), while higher proportions of jumper's knee and OsgoodSchlatter disease in males than in females were recognized in the $10-19$-year-old age group (12.5\% vs $1.8 \%)$ and the $20-29$-year-old age group ( $14.6 \%$ vs $3.7 \%$ ), respectively.

\section{Foot and ankle injuries}

Figure 2 shows that the proportion of ankle sprain was the highest (male: $58.0 \%$, female: $64.4 \%$ ), followed by stress

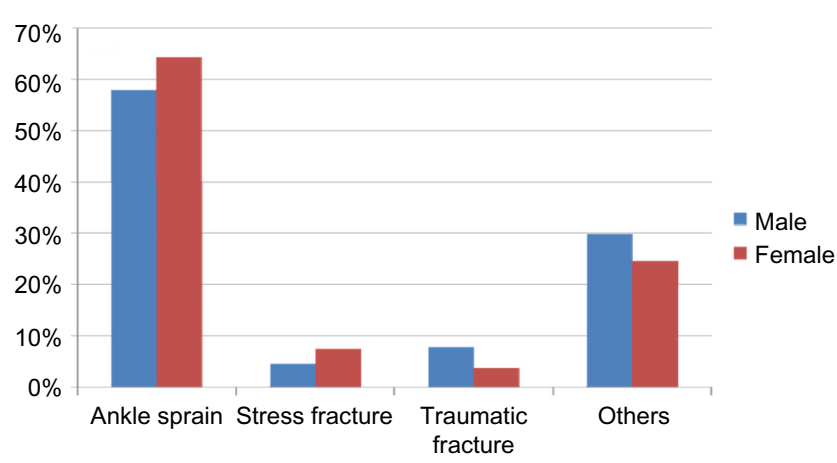

Figure 2 Foot and ankle injuries.

Notes: The graph shows the proportion of main injuries of the foot and ankle in male and female basketball players. The proportion of ankle sprain was the highest, followed by stress fracture and traumatic fracture. No significant differences in the proportions of these injuries were observed between male and female players (Fisher's exact test). fracture (male: $4.4 \%$, female $7.4 \%$ ) and traumatic fracture (male: $7.7 \%$, female: $3.7 \%$ ). No significant differences in the proportions of these injuries were observed between male and female players.

\section{Lower back injuries}

Figure 3 shows that the proportion of lumbar disk disease, except for lumbar disk herniation, was the highest (male: $32.6 \%$, female: $46.2 \%$ ), followed by spondylolysis (male: $16.3 \%$, female: $10.3 \%$ ) and lumbar disk herniation (male: $16.3 \%$, female: $9.0 \%$ ). No significant differences in the proportions of these injuries were observed between male and female players.

\section{Upper extremity injuries}

Figure 4 shows that the proportion of joint dislocation was the highest (male: $33.8 \%$, female: $25.7 \%$ ), followed by fracture (male: $22.5 \%$, female: $11.4 \%$ ) and ligament injury (male: $11.3 \%$, female: $22.9 \%$ ). No significant differences in the proportions of these injuries were observed between male and female players.

\section{Discussion}

An observational study with a retrospective case-series design was conducted to investigate sex-specific differences in the types of injuries sustained by basketball players. The foci of the discussion are 1) the common and specific injuries in basketball players in our clinical practice, and 2) the sexspecific differences in the type of injuries sustained while participating in this sport.

According to our database, the most common injury site in basketball players (mean age: 19.6 years) was the knee, followed by the foot and ankle. The surveillance of sports

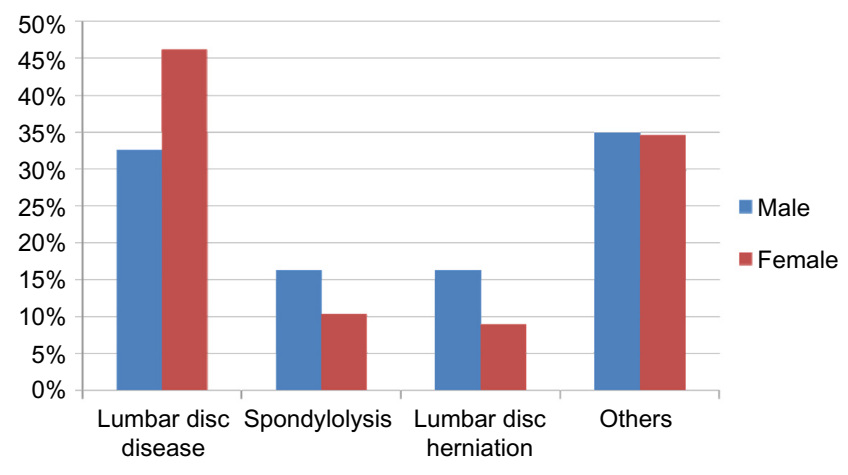

Figure 3 Lower back injuries.

Notes: The graph shows the proportion of main injuries of the lower back in male and female basketball players. The proportion of lumbar disc disease, except for lumbar disc herniation, was the highest, followed by spondylolysis and lumbar disc herniation. No significant differences in the proportions of these injuries were observed between male and female players (Fisher's exact test). 


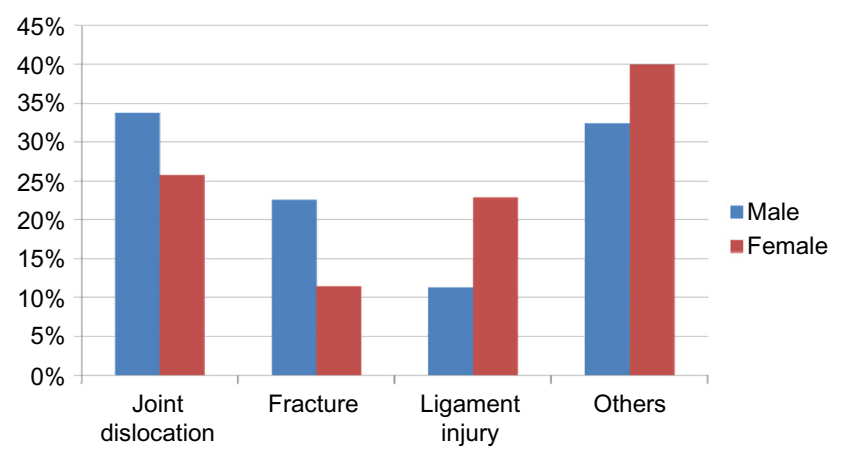

Figure 4 Upper extremity injuries.

Notes: The graph shows the proportion of main injuries of the upper extremity in male and female basketball players. The proportion of joint dislocation was the highest (male: $33.8 \%$, female: $25.7 \%$ ), followed by fracture and ligament injury. No significant differences in the proportions of these injuries were observed between male and female players (Fisher's exact test).

injuries in Japanese junior athletes clarified that the most common injury site was the ankle, followed by the finger, head, and knee. ${ }^{4}$ Fong et $\mathrm{al}^{5}$ reported that the ankle was ranked as the most highly injured body site in basketball. In elite basketball players, a lateral ankle sprain is the most common diagnosis. ${ }^{1-3}$ Although it is likely that ankle injuries are common among basketball players, there was a discrepancy with regard to the proportion of knee injuries. The high proportion of knee injury in the present study may be attributable to the large number of knee surgeons engaged in our sports medicine clinic. Another possibility is that many ankle-injured basketball players did not require or seek professional treatment, ${ }^{6}$ while athletes sustaining an ACL injury consulted experts. The lower extremities are certainly the most commonly injured body area in basketball players. The playing surface (a hard basketball court), which affects body weight loading on the lower extremity, and the repetitive actions of dashing, cutting, stopping, and jumping may increase the incidence of ankle and knee injuries in basketball players.

There was a higher proportion of female than male basketball players presenting with ACL injury (48.7\% vs $30.3 \%$ ). It is well known that the incidence of non-contact ACL injury is higher among female athletes than among male athletes. ${ }^{7}$ A video analysis study indicates a frontal plane "valgus collapse" mechanism for non-contact ACL injury in women. ${ }^{8}$ Non-contact ACL injuries often exhibit a common body posture that involves a valgus collapse of the knee joint, with the knee near full extension (between $0^{\circ}$ and $30^{\circ}$ ) and an external tibial rotation with the foot planted during a deceleration maneuver. ${ }^{9,10}$ Dynamic valgus collapse is the most common ACL injury mechanism for female handball and basketball players. ${ }^{9,11}$ Female basketball players have a 5.3-times higher relative risk of valgus collapse during ACL injury, compared with male basketball players. ${ }^{9}$ According to an International Olympic Committee current concept, risk factors for female athletes suffering ACL injury include 1) being in the preovulatory phase of the menstrual cycle, compared with the postovulatory phase; 2) having a decreased intercondylar notch width on plain radiography; and 3) the development of an increased knee abduction moment (a valgus intersegmental torque) during impact onloading. ${ }^{12}$ Thus, sex hormones, dynamic neuromuscular imbalance, and anatomy may play a role in the increased risk of non-contact ACL injury in female athletes. ${ }^{7}$

In the present study, among all the age groups, a higher proportion of ACL injury in female players was recognized in the 10-19-year-old age group. Sex differences exist in knee abduction during landing: female athletes land with a greater total valgus motion and a greater maximum valgus knee angle than male athletes. ${ }^{13}$ With the onset of puberty, marked changes in anatomy and posture occur in both males and females. Sex differences in femoral anteversion, the tibiofemoral angle, and the quadriceps angle emerge during puberty, with females maintaining a more inwardly rotated hip and valgus knee posture at full maturity. ${ }^{14}$ Thus, pubertyrelated increases in valgus knee angle and subsequently landing with greater valgus knee motion are considered to increase the risk of ACL injury in the 10-19-year-old age group of female basketball players.

There was a higher proportion of male than female basketball players presenting with Osgood-Schlatter disease and jumper's knee (patellar and femoral tendinopathy). Osgood-Schlatter disease was common among 10-12-year-old athletes, while jumper's knee was common among 20-29-year-old players. Patellar tendinopathy, or jumper's knee, is an injury that has a high prevalence in sports, especially those involving jumping, with reported prevalence of up to $45 \%$ and $32 \%$ in elite volleyball and basketball players, respectively. ${ }^{15}$ Generally, risk factors for patellar tendinopathy include body weight, body mass index, waist-to-hip ratio, leg-length difference, arch height of the foot, quadriceps flexibility, hamstring flexibility, quadriceps strength, and vertical jump performance; ${ }^{16}$ therefore, reducing body weight, increasing upper-leg flexibility and quadriceps strength, and the use of orthotics are suggested to be beneficial treatment options. ${ }^{16}$ In basketball players, the risk factors for patellar tendinopathy are reported to be age, playing at a national level, and being male. ${ }^{17}$ One possibility for the higher proportions of Osgood-Schlatter disease and jumper's knee among male basketball players in the present study may be a higher 
quadriceps muscle strength and tightness, resulting in the application of a greater traction force to the tibial tuberosity apophysis and patellar inferior and superior poles, compared with female basketball players.

The present study was not able to show differences in injuries during game vs practice and first vs recurrent injuries. Furthermore, because we did not record injury situations in our database, the mechanism of injury type among basketball players remains uncertain. It is known that the risk of injury during a game is higher than during practice. ${ }^{18-21}$ Preseason-practice injury rates are reported to be higher than regular-season-practice injury rates. ${ }^{21}$ The rate of ankle injury is high among basketball players, and the strongest predictor of ankle injuries is a history of ankle injury. ${ }^{6}$ Recurrent ankle injury is associated with chronic ankle instability. ${ }^{22}$ The above information including the mechanism of injury type is important to emphasize proper training and optimize performance.

The present study was also not able to assess body size, position on the court, years of basketball participation, and levels of competition. Yeh et $\mathrm{al}^{23}$ reported that risk of meniscus tears was increased in players having a body mass index greater than $25 \mathrm{~kg} / \mathrm{m}^{2}$. Vanderlei et $\mathrm{al}^{24}$ showed that the frequency of injury was highest among the shooting guards, followed by the centers and point guards, and that injuries were associated with weight among players. However, de Vries et $\mathrm{al}^{25}$ indicated that playing level (regional or national), years playing basketball or volleyball, average hours training per week, playing surface, training increase compared with last year, other sports, and average hours of other sports were not identified to increase the risk of developing patellar tendinopathy in basketball and volleyball players. Further studies are needed to clarify the association of the above factors with each major injury found in the present study.

The present study has several limitations. A local bias may exist in that our sports medicine clinic draws from a broad area and has specialists trained to differentiate between injuries. The sample sizes of male and female players and in age groups were not consistent so that the data obtained in the present study may not reflect the risk of injuries among male and female basketball players of various age groups accurately. Furthermore, it seems unlikely that all basketball players who sustained injury consult orthopedic surgeons in clinics. Finally, the present study may not be sufficient to assess the risk of injuries and sex differences in injuries, as it does not take into account activity participation rates.

In conclusion, according to our database, there was a higher proportion of female than male basketball players presenting with ACL injury, and there were higher proportions of male than female basketball players presenting with Osgood-Schlatter disease and jumper's knee. The present observational study, which had a retrospective case-series design, identified the most common injuries in basketball players, and revealed the existence of sex-specific differences in knee injuries sustained while participating in this sport.

\section{Disclosure}

The authors report no financial or other conflicts of interest in this work.

\section{References}

1. Deitch JR, Starkey C, Walters SL, Moseley JB. Injury risk in professional basketball player: a comparison of Women's National Basketball Association and National Basketball Association athletes. Am J Sports Med. 2006;34(7):1077-1083.

2. Kuzuhara K, Iguchi J, Inoue S, Mase Y. Analysis of injuries in professional players of a jb league team: a 3-year prospective study. Jpn J Clin Sports Med. 2013;21(1):187-193. Japanese.

3. Miki E, Shimizu Y. An effect and the prospects of the anterior cruciate ligament injury prevention: action in basketball. Clin Sports Med. 2012;29(11):1147-1154. Japanese.

4. Okuwaki T. Surveillance study of sport injuries in Japanese junior athletes. Jpn J Clin Sports Med. 2012;20(3):415-417. Japanese.

5. Fong DT, Hong Y, Chan LK, Yung PS, Chan KM. A systematic review on ankle injury and ankle sprain in sports. Sport Med. 2007;37(1): 73-94.

6. McKay GD, Goldie PA, Payne WR, Oakes BW. Ankle injuries in basketball: injury rate and risk factors. Br J Sports Med. 2001;35(2): 103-108.

7. Dugan SA. Sports-related knee injuries in female athletes: what gives? Am J Phys Med Rehabil. 2005;84(2):122-130.

8. Quatman CE, Hewett TE. The anterior cruciate ligament injury controversy: is "valgus collapse" a sex-specific mechanism? Br J sports Med. 2009;43(5):328-335.

9. Krosshaug T, Nakamae A, Boden BP, et al. Mechanisms of anterior cruciate ligament injury in basketball: video analysis of 39 cases. Am J Sports Med. 2007;35(3):359-367.

10. Boden BP, Dean GS, Feagin JA Jr, Garrett WE Jr. Mechanisms of anterior cruciate ligament injury. Orthopedics. 2000;23(6):573-578.

11. Olsen OE, Myklebust G, Engebretsen L, Bahr R. Injury mechanisms for anterior cruciate ligament injuries in team handball: a systematic video analysis. Am J Sports Med. 2004;32(4):1002-1012.

12. Renstrom $P$, Ljungqvist $A$, Arendt $E$, et al. Non-contact $A C L$ injuries in female athletes: an International Olympic Committee current concepts statement. Br J sports Med. 2008;42(6):394-412.

13. Ford KR, Myer GD, Hewett TE. Valgus knee motion during landing in high school female and male basketball players. Med Sci Sports Exerc. 2003;35(10): 1745-1750.

14. Shultz SJ, Nguyen AD, Schmitz RJ. Differences in lower extremity anatomical and postural characteristics in males and females between maturation groups. J Orthop Sports Phys Ther. 2008;38(3):137-149.

15. Lian OB, Engebretsen L, Bahr R. Prevalence of jumper's knee among elite athletes from different sports: a cross-sectional study. Am J Sports Med. 2005;33(4):561-567.

16. van der Worp H, van Ark M, Roerink S, Pepping GJ, van den AkkerScheek I, Zwerver J. Risk factors for patellar tendinopathy: a systematic review of the literature. Br J Sports Med. 2011;45(5):446-452.

17. van der Worp H, van Ark M, Zwerver J, van den Akker-Scheek I. Risk factors for patellar tendinopathy in basketball and volleyball players: a cross-sectional study. Scand J Med Sci Sports. 2012;22(6):783-790. 
18. Messina DF, Farney WC, DeLee JC. The incidence of injury in Texas high school basketball. A prospective study among male and female athletes. Am J Sports Med. 1999;27(3):294-299.

19. Harmer PA. Basketball injuries. Med Sport Sci. 2005;49:31-61.

20. Kofotolis N, Kellis E. Ankle sprain injuries: a 2-year prospective cohort study in female Greek professional basketball players. J Athl Train. 2007;42(3):388-394.

21. Agel J, Olson DE, Dick R, Arendt EA, Marshall SW, Sikka RS. Descriptive epidemiology of collegiate women's basketball injuries: National Collegiate Athletic Association Injury Surveillance System, 1988-1989 through 2003-2004. J Athl Train. 2007;42(2):202-210.

22. Attenborough AS, Hiller CE, Smith RM, Stuelcken M, Greene A, Sinclair PJ. Chronic ankle instability in sporting populations. Sports Med. 2014;44(11):1545-1556.
23. Yeh PC, Starkey C, Lombardo S, Vitti G, Kharrazi FD. Epidemiology of isolated meniscal injury and its effect on performance in athletes from the National Basketball Association. Am J Sports Med. 2012;40(3): 589-594.

24. Vanderlei FM, Bastos FN, de Lemes IR, Vanderlei LC, Júnior JN, Pastre CM. Sports injuries among adolescent basketball players according to position on the court. Int Arch Med. 2013;6(1):5.

25. de Vries AJ, van der Worp H, Diercks RL, van den Akker-Scheek I, Zwerver J. Risk factors for patellar tendinopathy in volleyball and basketball players: a survey-based prospective cohort study. Scand J Med Sci Sports. Epub August 5, 2014.

\section{Publish your work in this journal}

Open Access Journal of Sports Medicine is an international, peer-reviewed, open access journal publishing original research, reports, reviews and commentaries on all areas of sports medicine. The manuscript management system is completely online and includes a very quick and fair peer-review system.
Visit http://www.dovepress.com/testimonials.php to read real quotes from published authors. 